\title{
Determination of rhodamine $B$ content in terasi: an Indonesian traditional shrimp paste
}

\author{
Saptono Hadi*, Septi Ayu Saputri \\ Department of Pharmacy, faculty of Mathematics and Natural Sciences, Universitas Sebelas Maret, Indonesia
}

\begin{abstract}
Terasi is an Indonesia variety of shrimp paste, prepared from fermented extract of the Acetes species of marine shrimp. It is salty pink paste with pungent-odor, and commonly used as a cooking ingredient in many Southeast-Asian dishes. Traditionally, terasi is made from ground shrimp which is then fermented under the sun. Consumers generally prefer interesting purplered coloured terasi products, therefore manufacturers often add food colourants, such as rhodamine $\mathrm{B}$, into their products in order to obtain the desired colour. Rhodamine B is one of the colouring agents which is banned for food according to Indonesia Food and Drugs Supervisory Agency or BPOM.
\end{abstract}

Samples were obtained from the city of Serang, Banten, which is one of the major production centre of terasi in Indonesia. A total of ten samples were collected from four traditional markets in Serang, Banten, i.e. Ciruas, Cikande, Rau, and Tambak. Samples were purposively chosen based on criteria: the products are unregistered by BPOM, which consist of labelled and unlabelled products. All samples have low prices and were selected which have a reddish colour. The samples were extracted using methanol and $\mathrm{HCl}$ and qualitatively analyzed in duplicate using CMR reagents. To positive samples, quantitative analysis were further done in triplicate using a validated UV-Vis spectrophotometry method.

The results showed that qualitative test using CMR reagents found seven samples $(70 \%)$ of shrimp paste samples positive containing rhodamine B. Furthermore, replicate analyses of sample found range concentration of rhodamin B were $11.97 \square 98.33 \mathrm{mg} / \mathrm{kg}$ fresh weight. The average level of rhodamine $\mathrm{B}$ in unlabelled products were significantly higher than those in labelled products $(71.87>26.44 \mathrm{mg} / \mathrm{kg}$ fresh weight). The levels obtained, however, still far below the minimum toxic doses of rhodamin B for a single ingestion which is $500 \mathrm{mg} / \mathrm{kg} \mathrm{BW}$ according to the BPOM. Nevertheless, these results indicate the importance of continuous monitoring of illegal use of rhodamine B in traditional food.

Keywords: Terasi shrimp paste, rhodamin B, UV-Vis spectrophotometry 